\title{
Antibakterielle In-vitro-Wirksamkeit ätherischer Öle gegen veterinärmedizinisch relevante Keime klinischer Isolate von Hunden, Katzen und Pferden
}

\author{
Doris Bismarck Marianne Schneider Elisabeth Müller
}

Laboklin GmbH \& Co. KG, Bad Kissingen, Deutschland

\section{Schlüsselwörter \\ Ätherische Öle · Antibakterielle Wirkung · Veterinärmedizin . Aromatogramm}

\section{Zusammenfassung}

Einleitung: Ätherische Öle sind die Grundlage der Aromatherapie. Unter anderem wird innen eine antibakterielle Wirkung zugeschrieben. In dieser Studie sollte die In-vitro-Wirksamkeit ätherischer Öle gegen ein breites Spektrum veterinärmedizinisch relevanter Erreger getestet werden. Methoden: Die antibakterielle Aktivität von 16 ätherischen Ölen wurde mittels Agardiffusionstest bestimmt. Getestet wurden grampositive und gramnegative Erreger, die aus klinischen Isolaten von Hunden, Katzen und Pferden aus der veterinärmedizinischen Routinediagnostik stammten. Die Einteilung der Wirksamkeit in nicht, gering-, mittel- und hochgradig wirksam erfolgte anhand der Größe der Hemmhofradien des Bakterienwachstums. Ergebnisse: Generell zeigten sich sowohl grampositive als auch gramnegative Erreger empfindlich gegen einige der getesteten ätherischen Öle. Nicht nur gegen Staphylokokken, sondern auch gegen Methicillin-resistente Stämme der Staphylokokken wiesen die ätherischen Öle in vitro eine nicht zu vernachlässigende Wirkung auf. Pasteurella multocida stellte sich als eher sensibler Keim heraus, während Pseudomonas aeruginosa als vollkommen resistenter Keim eine Ausnahme bildete. Teebaum-, Oregano-, und Bergbohnenkrautöl waren die potentesten Öle. Zusätzlich zeigten sich bei den grampositiven Erregern Lemongrasöl und bei den gramnegativen Erregern Thymianöl als gut wirksam. Schlussfolgerung: Ätherische Öle verfügen in vitro über eine antibakterielle Aktivität gegen klinische Isolate von Hunden, Katzen und Pferden. Diese Studie bietet eine Grundlage für die Anwendung ätherischer Öle in der Veterinärmedizin. Es zeichneten sich Tendenzen im Wirkspektrum einzelner ätherischer Öle bzw. im Grad der Wirksamkeit ätherischer Öle hinsichtlich einzelner Erregerspezies ab, allerdings lässt sich keine sichere Vorhersage über ihre Wirksamkeit gegen einen spezifischen Keim eines individuellen Patienten treffen. Deswegen sollte vor einer Therapie mit ätherischen Ölen deren individuelle Wirksamkeit mittels Aromatogramm getestet werden.

\section{Keywords}

Essential oils - Antibacterial activity · Veterinary medicine . Aromatogram

\section{Summary}

In vitro Antibacterial Activity of Essential Oils against Bacteria of Veterinary Relevance from Clinical Isolates of Dogs, Cats, and Horses

Introduction: Essential oils are the basis for aromatherapy. They are supposed to have an antibacterial activity. The aim of this study was to determine the in vitro antibacterial activity of essential oils against a broad range of clinical isolates of bacteria which are relevant for veterinary medicine. Methods: The antibacterial activity of 16 essential oils was detected using the agar diffusion test. Gram-positive and gram-negative bacteria of clinical isolates of dogs, cats, and horses from veterinary routine diagnostic were used. Classification of antibacterial activity in not, lowly, moderately, and highly effective resulted from the size of the zone of inhibition of bacterial growth. Results: Overall, gram-positive and gram-negative bacteria were susceptible against essential oils. They showed an in vitro antibacterial activity against staphylococci including methicillin-resistant strains. Pasteurella multocida was rather sensitive, in great contrast to the totally resistant Pseudomonas aeruginosa. Tea tree, oregano, and winter savory oil seemed to be the most potent oils. In addition, lemongrass oil and thyme oil showed a good activity against gram-positive and gram-negative bacteria, respectively. Conclusion: Essential oils have an in vitro antibacterial activity against clinical isolates of dogs, cats, and horses. This study conducts basic information for the use of essential oils in veterinary medicine. Clearly, tendencies in the spectrum of efficacy of essential oils can be found, but no generalizing assertion about their activity against specific pathogenic bacteria in an individual patient should be made. Thus, before the beginning of a therapy with essential oils, their respective individual activity should be tested by an aromatogram.

\section{KARGER}

Fax +497614520714 Information@Karger.com www.karger.com (c) 2017 The Author(s)
Published by S. Karger GmbH, Freiburg
Open access

This article is licensed under the Creative Commons AttributionNonCommercial-NoDerivatives 4.0 International License (CC BY-NCND 4.0) (http://www.karger.com/Services/OpenAccessLicense). Usage tion for commercial purposes as well as any distribution of modified material requires written permission.

\author{
Dr. Doris Bismarck \\ Laboklin GmbH \& Co. KG \\ Steubenstraße 4, 97688 Bad Kissingen, Deutschland \\ bismarck@laboklin.com
}




\section{Einleitung}

Aufgrund der stetig steigenden Anzahl bakterieller Resistenzen gegen Antibiotika ist es heutzutage und auch in Zukunft wichtig, alternative Behandlungsmethoden gegen bakterielle Infektionen in Betracht zu ziehen. Zusätzlich gibt es mittlerweile in der Tiermedizin, wie auch in der Humanmedizin, ein steigendes Interesse an natürlichen, pflanzenbasierten Therapiemethoden.

Bei ätherischen Ölen handelt es sich um Phytotherapeutika, die wasserdampfflüchtige, niedermolekulare Vielstoffgemische lipophiler Verbindungen darstellen [1]. Sie werden in der Regel durch Wasserdampfdestillation aus Ätherischölpflanzen gewonnen, in denen sie in Ölräumen wie den Drüsenhaaren, Drüsenzellen oder Ölbehältern abgelagert sind. Ätherische Öle als Vielstoffgemische enthalten im Allgemeinen als bestimmende Inhaltsstoffe Terpene (Mono-, Sesqui- und Diterpene) und/oder Phenylpropane [2].

In der Tiermedizin können ätherische Öle oder Bestandteile ätherischer Öle als Repellents oder Pestizide gegen Ektoparasiten genutzt werden [3]. Zusätzlich gibt es Studien, die auf eine beruhigende Wirkung von Lavendelöl auf Pferde [4] und Labormäuse [5] hindeuten. Bei Hunden und Schafen konnte diese beruhigende Wirkung nicht eindeutig bewiesen werden $[6,7]$.

Klinische Untersuchungen zeigten, dass eine Behandlung von an atopischer Dermatitis und an nicht generalisierter Dermatitis erkrankten Hunden mit kommerziell erhältlichen Formulierungen, die unter anderem ätherische Öle enthielten, zu einer Besserung der Symptomatik führten [8-10]. Ebenfalls zeigte sich bei bakteriell bedingter oberflächlicher Pyodermie durch eine zusätzlich zur antibiotischen Therapie durchgeführte topische Behandlung mit einem Manukaöl enthaltenden Präparat eine schnellere klinische Besserung, die unter anderem durch die antibakterielle Wirkung des Manukaöls bedingt sein könnte [11]. Mundspüllösungen mit ätherischen Ölen, z.B. von Lippia sidoides Cham., führten bei Hunden zu einer Reduktion von Gingivitis, die auch mit einem Rückgang von plaquebildenden Bakterien einhergeht [12]. Eine Behandlung von Prostataabszessen bei Hunden mit Teebaumöl nach Aspiration eitrigen Materials erwies sich als sehr effektiv [13].

Die antibakterielle Wirkung ätherischer Öle ist aus humanmedizinischen und auch lebensmitteltechnischen Studien bekannt [2, 14-17]. Zur konkreten antibakteriellen Wirkung einzelner ätherischer Öle gegen spezifisch veterinärmedizinisch relevante Bakterien gibt es einzelne In-vitro-Studien. Thymian-, Oregano-, Teebaum-, Nelken-, Zimtblätter-, Lemongras- und Muskatellersalbeiöl erwiesen sich in vitro als wirksam gegen Referenzstämme von Staphylococcus (S.) aureus, Enterococcus faecalis, Escherichia (E.) coli, Pseudomonas (P.) aeruginosa, Proteus mirabilis und Klebsiella pneumoniae $[18,19]$. Eine Studie belegte zwar eine gute Wirksamkeit von Salbeiöl gegen bakterielle Referenzstämme, allerdings eine verringerte bis schlechte Wirksamkeit gegen klinische Keimisolate [20, 21]. Damit liegt die Untersuchung klinischer Isolate nahe. Einige wenige In-vitro-Studien mit veterinärmedizinischen klinischen Keimisolaten wurden bereits durchgeführt: Zum Beispiel erwies sich Manukaöl als wirksam gegen $S$. pseudintermedius von Hunden mit Pyodermie oder Otitis externa [22]. Nelkenöl war wirksam gegen E. coli, Klebsiellen und Proteus-Arten, die aus dem Muskelmagen von Puten isoliert wurden [23]. Zimtblätter-, Lemongras- und Oreganoöl wirkten antibakteriell gegen S.-aureusMastitis-Isolate von Kühen und Ziegen [24, 25]. Thymian-, Lavendel- und Oreganoöl zeigten z.B. eine Wirksamkeit gegen S. aureus und E. coli [26].

Generell wird vermutetet, dass die antimikrobielle Wirksamkeit der Vielstoffgemische der ätherischen Öle ein kumulativer Effekt der Wirkung ihrer Einzelbestandteile mit unterschiedlichen zellulären Angriffspunkten ist [27].

Für eine gezielte Therapie mit ätherischen Ölen sollte vor Beginn zuerst die Wirksamkeit einzelner ätherischer Öle gegen den spezifischen Krankheitserreger getestet werden - ähnlich einem Antibiogramm für eine antibiotische Therapie. Dafür steht im Labor z.B. das Aromatogramm zur Verfügung [28, 29]. Hierbei handelt es sich um einen Agardiffusionstest zur Empfindlichkeitsbestimmung.

Im Gegensatz zu vielen anderen Untersuchungen, wurde in der vorliegenden Studie die In-vitro-Wirksamkeit von 16 ätherischen Ölen gegen ein breites Spektrum an klinischen Bakterienisolaten von Hunden, Katzen und Pferden aus der veterinärmedizinischen Routinediagnostik mittels Aromatogramm getestet. Diese Studie bietet somit einen breiten Vergleich der Wirksamkeit dieser ätherischen Öle gegen veterinärmedizinisch relevante Keime und eine praxisrelevante Grundlage für ihre Anwendung in der Veterinärmedizin.

\section{Material und Methoden}

\section{Bakterielle Keimisolate}

Getestet wurden 179 klinische Keimisolate von Urin- $(\mathrm{n}=17)$, Haar- $(\mathrm{n}=$ 4) oder Tupferproben $(n=158)$ unterschiedlicher Lokalisationen von 114 Hunden, 24 Katzen und 41 Pferden, die aus der veterinärmedizinischen Routinediagnostik der Firma Laboklin GmbH \& Co. KG stammten (nähere Informationen zum Probenmaterial, zu den Lokalisationen und den Tierarten finden sich in Tab. 1 und 2).

Das eingesandte Material wurde auf Columbia-Agar mit 5\% Schafblut (BD Columbia Agar with 5\% Sheep Blood; Becton Dickinson GmbH, Heidelberg, Deutschland) und Endo-Agar (BD Endo Agar; Becton Dickinson GmbH, Heidelberg, Deutschland) fraktioniert ausgestrichen oder im Falle von Flüssigkeiten ausplattiert und für $24 \mathrm{~h}$ bei $36 \pm 1^{\circ} \mathrm{C}$ inkubiert. Zusätzlich erfolgte bei Tupfer- und Urinproben eine Anreicherung in einer Thioglycolat-Bouillon (BD, Becton Dickinson, Heidelberg, Deutschland) bei $37^{\circ} \mathrm{C}$ für $24 \mathrm{~h}$. Dieses Anreicherungsmedium wurde nach der Inkubation ebenfalls auf ColumbiaAgar mit 5\% Schafblut (Becton Dickinson GmbH) und Endo-Agar (Becton Dickinson $\mathrm{GmbH}$ ) ausgestrichen und für weitere $24 \mathrm{~h}$ bei $37^{\circ} \mathrm{C}$ inkubiert.

Die anschließende Keimidentifizierung erfolgte anhand der Koloniemorphologie in Kombination mit ihren Wachstumseigenschaften auf den genannten Selektivnährmedien und/oder anschließend mittels MALDI-TOF Massenspektrometer (AXIMA Assurance, Shimadzu, Duisburg, Deutschland). Die Auswahl der von Hunden, Katzen und Pferden stammenden Keimisolate erfolgte zufällig. Einzelkolonien der ausgewählten Keime wurden zur weiteren Bearbeitung im Aromatogramm erneut auf Columbia-Agar mit 5\% Schafblut ausgestrichen und für $24 \mathrm{~h}$ inkubiert.

Zusätzlich wurde das Wachstum aller Staphylokokken, S. aureus und S. pseudintermedius, auf dem Brilliance MRSA 2 Agar (Thermo Fisher Scientific, Braunschweig, Deutschland) getestet. Die Methicillin-resistenten Stämme von S. aureus (MRSA) und S. pseudintermedius (MRSP) wurden anhand ihres ex- 
Tab. 1. Aufgelistet sind die im Agardiffusionstest getesteten grampositiven Keime, mit Ursprung der klinischen Isolate nach Tierart und Lokalisation; die Probenanzahl beträgt $n=1$, wenn nicht direkt hinter der Probe eine andere Angabe steht

\begin{tabular}{|c|c|c|c|}
\hline $\begin{array}{l}\text { Grampositive Keime } \\
\text { (Anzahl) }\end{array}$ & Hund $(n=42)$ & Katze $(\mathrm{n}=8)$ & Pferd $(n=10)$ \\
\hline $\begin{array}{l}\text { Staphylococcus aureus } \\
\qquad(\mathrm{n}=10)\end{array}$ & $\begin{array}{l}\text { Abstrich: } \\
\text { Kniegelenk / unbekannt }\end{array}$ & $\begin{array}{l}\text { Abstrich: } \\
\text { Haut / Nase / unbekannt } \\
\text { Haarprobe }\end{array}$ & $\begin{array}{l}\text { Abstrich: } \\
\text { Haut / Nase / Rachen } \\
\text { Haarprobe }\end{array}$ \\
\hline MRSA $(n=10)$ & $\begin{array}{l}\text { Abstrich: } \\
\text { Ohr / Wunde / Thoraxerguss / } \\
\text { unbekannt }\end{array}$ & $\begin{array}{l}\text { Abstrich: } \\
\text { unbekannt }\end{array}$ & $\begin{array}{l}\text { Abstrich: } \\
\text { Venenentzündung / Nase / } \\
\text { Abszess / unbekannt }(\mathrm{n}=2)\end{array}$ \\
\hline $\begin{array}{l}\text { Staphylococcus } \\
\qquad \begin{array}{l}\text { pseudintermedius } \\
(\mathrm{n}=10)\end{array}\end{array}$ & $\begin{array}{l}\text { Abstrich: } \\
\text { Haut / Ohr }(\mathrm{n}=4) \text { / Kralle / } \\
\text { Vagina }(\mathrm{n}=2) \text { / unbekannt } \\
\text { Haarprobe }\end{array}$ & keine Probe & keine Probe \\
\hline $\operatorname{MRSP}(\mathrm{n}=10)$ & $\begin{array}{l}\text { Abstrich: } \\
\text { Ohr }(\mathrm{n}=2) / \text { Haut / Rachen } \\
(\mathrm{n}=2) / \text { Harn / Analfistel / } \\
\text { unbekannt }(\mathrm{n}=2) \\
\text { Haarprobe }\end{array}$ & keine Probe & keine Probe \\
\hline $\begin{array}{l}\text { Beta-hämolysierende } \\
\text { Streptokokken } \\
(\mathrm{n}=10)\end{array}$ & $\begin{array}{l}\text { Abstrich: } \\
\text { Ohr }(\mathrm{n}=4) / \text { Maul / Pfote } \\
(\mathrm{n}=2) / \text { unbekannt } \\
\text { Harnprobe }\end{array}$ & Harnprobe & keine Probe \\
\hline Enterokokken $(\mathrm{n}=10)$ & $\begin{array}{l}\text { Abstrich: } \\
\text { Ohr }(\mathrm{n}=3) / \text { Haut / Pfote / } \\
\text { Harn } \\
\text { Harnprobe }\end{array}$ & $\begin{array}{l}\text { Abstrich: } \\
\text { unbekannt } \\
\text { Harnprobe }\end{array}$ & $\begin{array}{l}\text { Abstrich: } \\
\text { TBS }\end{array}$ \\
\hline
\end{tabular}

klusiven Wachstums auf diesem Agar identifiziert. Bei der Mikrodilution (MICRONAUT S; Merlin, Bornheim-Hersel, Deutschland) zeigten sich zudem die MRSA-Keime resistent für das Antibiotikum Cefoxitin und die MRSP-Keime resistent für das Antibiotikum Oxacillin mittels und gelten somit nach dem Clinical and Laboratory Standards Institute (CLSI) als multiresistent [30]. Staphylokokken, die kein Wachstum auf dem Brilliance MRSA 2 Agar (Thermo Fisher Scientific) zeigten, waren im Fall von S.aureus sensibel gegen Cefoxitin und im Fall von S. pseudintermedius sensibel gegen Oxacillin und somit keine multiresistenten Keime.

\section{Aromatogramm}

$100 \mu \mathrm{l}$ einer Bakteriensuspension (in $\mathrm{NaCl}, \mathrm{McF}$ arland 0,5) wurden auf einer Müller-Hinton-Agarplatte (BD Mueller Hinton II Agar; Becton Dickinson, Heidelberg, Deutschland) oder im Fall von Pasteurella multocida und betahämolysierenden Streptokokken auf einer Müller-Hinton-Agarplatte mit 5\% Schafblut (BD Mueller Hinton II with 5\% Sheep Blood; Becton Dickinson, Hei delberg, Deutschland) ausplattiert. Anschließend wurden Filterpapierplättchen (BBL ${ }^{\mathrm{TM}}$ Sensi-Disc ${ }^{\mathrm{TM}}$ Susceptibility Test Disc, Blanc Disc; Becton Dickinson, Heidelberg, Deutschland) auf die Agarplatte aufgebracht, die dann jeweils mit $10 \mu \mathrm{l}$ des zu testenden ätherischen Öls beschickt wurden. Der Ansatz verblieb 0,5 h bei Raumtemperatur, um die Diffusion der Öle in den Agar zu gewährleisten. Anschließend wurden die Platten für $24 \mathrm{~h}$ bei $36 \pm 1{ }^{\circ} \mathrm{C}$ inkubiert. Die Auswertung erfolgte durch die Bestimmung der Hemmhofradien bzw. durch die Feststellung eines fehlenden Bakterienwachstums um die mit ätherischem Öl beschickten Filterpapierplättchen. Die Einteilung der In-vitroWirksamkeit erfolgte nach steigender Größe des Hemmhofradius in 4 Stufen von «nicht wirksam» $(<8 \mathrm{~mm})$ über «gering-» $(8-13 \mathrm{~mm})$ und «mittel-» (14-
$19 \mathrm{~mm}$ ) bis «hochgradig wirksam» ( $\geq 20 \mathrm{~mm})$. Das Aromatogramm wurde für jedes getestetes Keimisolat in Unikaten einmalig durchgeführt.

Die antibakterielle Aktivität der in Tabelle 3 aufgeführten 100\% naturreinen, kommerziell erhältlichen ätherischen Öle wurde bestimmt. Nähere Informationen zur Zusammensetzung der ätherischen Öle finden sich in der Online Supplemental Tabelle (Online Supplemental Material; www.karger. $\mathrm{com} /$ ?DOI=465519).

\section{Ergebnisse}

\section{Empfindlichkeit der bakteriellen Erreger}

Sowohl grampositive als auch gramnegative Erreger erwiesen sich in vitro als empfindlich gegen unterschiedliche ätherische Öle.

Unter den grampositiven Erregern (Abb. 1) zeigten sich die Staphylokokken als empfindlich, hauptsächlich gegen Teebaum-, Bergbohnenkraut-, Oregano-, Lemongras- und Manukaöl. S. pseudintermedius wies gegenüber $S$. aureus eine etwas höhere Empfindlichkeit auf. Beta-hämolysierende Streptokokken waren im Vergleich zu den Staphylokokken etwas resistenter und hauptsächlich empfindlich gegen Bergbohnenkraut-, Oregano-, Nelkenblütenund Lemongrasöl. Enterokokken erwiesen sich unter den grampositiven Erregern als am resistentesten. Hier waren hauptsächlich nur Bergbohnen-, Oregano- und Lemongrasöl gering wirksam. 
Tab. 2. Aufgelistet sind die im Agardiffusionstest getesteten gramnegativen Keime mit Ursprung der klinischen Isolate nach Tierart und Lokalisation; die Probenanzahl nicht direkt hinter der Probe eine andere Angabe steht beträgt $\mathrm{n}=1$, wenn

\begin{tabular}{|c|c|c|c|}
\hline $\begin{array}{l}\text { Gramnegative Keime } \\
\text { (Anzahl) }\end{array}$ & Hund $(\mathrm{n}=72)$ & Katze $(n=16)$ & Pferd $(n=31)$ \\
\hline Escherichia coli $(\mathrm{n}=15)$ & $\begin{array}{l}\text { Abstrich: } \\
\text { Ohr / Lefze / Rachen / Wunde / } \\
\text { Vagina / Harn }(n=4) \text { / unbekannt } \\
\text { Harnprobe }\end{array}$ & $\begin{array}{l}\text { Abstrich: } \\
\text { Nase }\end{array}$ & $\begin{array}{l}\text { Abstrich: } \\
\text { Nase }(\mathrm{n}=2) / \text { Penis }\end{array}$ \\
\hline $\begin{array}{l}\text { Hämolysierender } \\
\qquad \begin{array}{l}\text { Escherichia coli } \\
(\mathrm{n}=20)\end{array}\end{array}$ & $\begin{array}{l}\text { Abstrich: } \\
\text { Nase / Nasenfalte / Harn }(\mathrm{n}=4) \text { / } \\
\text { Analdrüse / Vagina }(\mathrm{n}=2) / \\
\text { unbekannt }(\mathrm{n}=4) \\
\text { Harnprobe }(\mathrm{n}=4)\end{array}$ & Harnprobe $(\mathrm{n}=3)$ & keine Probe \\
\hline $\begin{array}{l}\text { Klebsiella pneumoniae } \\
\qquad(\mathrm{n}=18)\end{array}$ & $\begin{array}{l}\text { Abstrich: } \\
\text { Auge / Maul / Rachen }(\mathrm{n}=2) \text { / } \\
\text { Tonsillen / Trachea / Vagina / } \\
\text { unbekannt }(\mathrm{n}=3)\end{array}$ & keine Probe & $\begin{array}{l}\text { Abstrich: } \\
\text { Auge }(\mathrm{n}=2) \text { / Nasensekret / } \\
\text { Nase / TBS / Vagina }(\mathrm{n}=3)\end{array}$ \\
\hline $\begin{array}{l}\text { Pantoea agglomerans } \\
\qquad(\mathrm{n}=17)\end{array}$ & keine Probe & keine Probe & $\begin{array}{l}\text { Abstrich: } \\
\text { Auge / Nase }(n=9) / \text { Rachen / } \\
\text { Gingivia }(n=2) / \text { Abszess / } \\
\text { unbekannt }(n=3)\end{array}$ \\
\hline $\begin{array}{l}\text { Acinetobacter } \\
\quad \text { baumannii }(\mathrm{n}=10)\end{array}$ & $\begin{array}{l}\text { Abstrich: } \\
\text { Nase }(\mathrm{n}=2) / \text { Trachea / Ohr / } \\
\text { unbekannt }(\mathrm{n}=2) \\
\text { Harnprobe }\end{array}$ & Harnprobe & $\begin{array}{l}\text { Abstrich: } \\
\text { Nase }(n=2)\end{array}$ \\
\hline $\begin{array}{l}\text { Proteus mirabilis } \\
\qquad(\mathrm{n}=19)\end{array}$ & $\begin{array}{l}\text { Abstrich: } \\
\text { Ohr }(\mathrm{n}=5) \text { / Kralle / Pfote / } \\
\text { Wunde / Analdrüse }(\mathrm{n}=3) / \\
\text { Vagina / Harn / unbekannt }(\mathrm{n}=3) \\
\text { Harnprobe }(\mathrm{n}=2)\end{array}$ & Harnprobe & keine Probe \\
\hline $\begin{array}{l}\text { Pasteurella multocida } \\
\qquad(\mathrm{n}=10)\end{array}$ & keine Probe & $\begin{array}{l}\text { Abstrich: } \\
\text { Nase }(\mathrm{n}=5) / \text { Ohr / BAL / } \\
\text { Gingivia / Wunde }(\mathrm{n}=2)\end{array}$ & keine Probe \\
\hline $\begin{array}{l}\text { Pseudomonas } \\
\quad \text { aeruginosa }(\mathrm{n}=10)\end{array}$ & $\begin{array}{l}\text { Abstrich: } \\
\text { Ohr }(\mathrm{n}=5) / \text { unbekannt }(\mathrm{n}=4)\end{array}$ & & $\begin{array}{l}\text { Abstrich: } \\
\text { TBS }\end{array}$ \\
\hline
\end{tabular}

Bei den gramnegativen Erregern (Abb. 2) zeigte sich Pasteurella multocida als empfindlichster Keim. Lediglich 3 ätherische Öle, Angelikawurzel-, Muskatellersalbei- und Lavendelöl fein, zeigten keinerlei Wirksamkeit. Acinetobacter baumannii und Pantoea agglomerans waren auch relativ empfindlich, hauptsächlich gegen Thymian-, Teebaum-, Bergbohnenkraut- und Oreganoöl, aber auch in etwas reduzierter Form gegen Nelkenblüten-, Zimtblätter-, Lemongras-, Ravintsara- und Lavendelöl fein. E. coli und E. coli mit hämolysierenden Eigenschaften waren nur noch empfindlich gegen Thymian-, Teebaum-, Bergbohnenkraut- und Oreganoöl. Keime wie Proteus mirabilis und Klebsiella pneumoniae waren resistenter. Sie zeigten sich ebenfalls empfindlich gegen diese ätherischen Öle, aber vorwiegend nur noch geringgradig. Eine Ausnahme unter den gramnegativen Erregern bildete $P$. aeruginosa, der gegen alle ätherischen Öle resistent war.

\section{Wirksamkeit einzelner ätherischer Öle}

Gegen grampositive Erreger (Abb. 1) waren Teebaum-, Bergbohnenkraut-, Oregano- und Lemongrasöl die wirksamsten ätherischen Öle. Besonders das Lemongrasöl zeigte bei $80-100 \%$ der Staphylokokkenisolate eine teils sogar hochgradige Wirksamkeit. Bergbohnenkraut- und Oreganoöl erwiesen sich ebenfalls in hohem Maße als als gering- oder mittelgradig wirksam, wohingegen Teebaumöl, wenn überhaupt, in erster Linie eher geringgradig wirksam war. Manukaöl zeigte auch gegen mindestens $70 \%$ der Staphylokokkenisolate eine geringgradige Wirkung, nicht jedoch gegen beta-hämolysierende Streptokokken oder Enterokokken. Indisches (ind.) Melissenöl wirkte in mindestens 80\% der Fälle geringgradig gegen S. pseudintermedius. Thymian-, Nelkenblüten-, Zimtblätter-, Palmarosa-, Musaktellersalbei-, Rosengeranien-, Ravintsara- und Lavendelöl fein waren gegen grampositive Keime eher selten wirksam und dann auch fast nur ge- 
Tab. 3. Aufgelistet sind alle im Agardiffusionstest getesteten ätherischen Öle, mit wissenschaftlichem Ölnamen, botanischem Namen der Stammpflanze und Angaben zu Inhaltsstoffen, Pflanzenteilen, Ursprungsland und Anbau nach Etikett des Herstellers

\begin{tabular}{|c|c|c|c|c|c|c|c|}
\hline \multirow{2}{*}{$\begin{array}{l}\text { Ätherisches Öl, } \\
100 \% \text { naturrein }\end{array}$} & \multirow{2}{*}{$\begin{array}{l}\text { Wissen- } \\
\text { schaftlicher } \\
\text { Ölname }\end{array}$} & \multirow{2}{*}{$\begin{array}{l}\text { Botanischer Name } \\
\text { der Stammpflanze }\end{array}$} & \multicolumn{4}{|c|}{ Angaben nach Etikettierung des Herstellers } & \multirow[t]{2}{*}{ Hersteller } \\
\hline & & & Inhaltsstoffe (INCI) & Pflanzenteil & $\begin{array}{l}\text { Ursprungsland/ } \\
\text { Anbau }\end{array}$ & Gewinnung & \\
\hline Fenchelöl & $\begin{array}{l}\text { Foeniculi } \\
\text { aetheroleum }\end{array}$ & $\begin{array}{l}\text { Foeniculum vulgare } \\
\text { var. dulce (MilL.) } \\
\text { BATT. Eт TrAB. }\end{array}$ & $\begin{array}{l}\text { Foeniculum vulgaris } \\
\text { oil (var. dulce), } \\
\text { Limonene, Linalool }\end{array}$ & Samen & $\begin{array}{l}\text { Russland, } \\
\text { kontrollierter } \\
\text { Bio-Anbau }\end{array}$ & $\begin{array}{l}\text { Wasserdampf- } \\
\text { destillation }\end{array}$ & $\begin{array}{l}\text { TAOMED }^{\circledR} \text {, } \\
\text { TAOASIS GmbH, } \\
\text { Detmold, } \\
\text { Deutschland }\end{array}$ \\
\hline Thymianöl & $\begin{array}{l}\text { Thymi ae- } \\
\text { theroleum }\end{array}$ & Thymus vulgaris $\mathrm{L}$. & $\begin{array}{l}\text { Thymus vulgaris oil, } \\
\text { Linalool, } \\
\text { Geraniol }\end{array}$ & $\begin{array}{l}\text { blühende } \\
\text { Pflanze }\end{array}$ & $\begin{array}{l}\text { Spanien, } \\
\text { kontrollierter } \\
\text { Bio-Anbau }\end{array}$ & $\begin{array}{l}\text { Wasserdampf- } \\
\text { destillation }\end{array}$ & $\begin{array}{l}\text { TAOMED }^{\circledR}, \\
\text { TAOASIS GmbH, } \\
\text { Detmold, } \\
\text { Deutschland }\end{array}$ \\
\hline Teebaumöl & $\begin{array}{l}\text { Melaleucae } \\
\text { aetheroleum }\end{array}$ & $\begin{array}{l}\text { Melaleuca } \\
\text { alternifolia CHEEL }\end{array}$ & $\begin{array}{l}\text { Melaleuca } \\
\text { alternifolia leaf oil, } \\
\text { Limonene, Linalool }\end{array}$ & Blatt & $\begin{array}{l}\text { Australien, } \\
\text { kontrollierter } \\
\text { Bio-Anbau }\end{array}$ & $\begin{array}{l}\text { Wasserdampf- } \\
\text { destillation }\end{array}$ & $\begin{array}{l}\text { TAOMED }^{\circledR}, \\
\text { TAOASIS GmbH, } \\
\text { Detmold, } \\
\text { Deutschland }\end{array}$ \\
\hline $\begin{array}{l}\text { Bergbohnen- } \\
\text { krautöl }\end{array}$ & $\begin{array}{l}\text { Saturejae } \\
\text { montanae } \\
\text { aetheroleum }\end{array}$ & Satureja montana $\mathrm{L}$. & $\begin{array}{l}\text { Satureja montana } \\
\text { oil }\end{array}$ & Kraut & $\begin{array}{l}\text { Kroatien, } \\
\text { kontrollierter } \\
\text { Bio-Anbau }\end{array}$ & $\begin{array}{l}\text { Wasserdampf- } \\
\text { destillation }\end{array}$ & $\begin{array}{l}\text { TAOMED }^{\circledR}, \\
\text { TAOASIS GmbH, } \\
\text { Detmold, } \\
\text { Deutschland }\end{array}$ \\
\hline Oreganoöl & $\begin{array}{l}\text { Origani ae- } \\
\text { theroleum }\end{array}$ & Origanum vulgare $\mathrm{L}$. & $\begin{array}{l}\text { Origanum vulgare oil, } \\
\text { Linalool, } \\
\text { Limonene, Geraniol, } \\
\text { Citral, Eugenol }\end{array}$ & Kraut & $\begin{array}{l}\text { Albanien, } \\
\text { kontrollierter } \\
\text { Bio-Anbau }\end{array}$ & $\begin{array}{l}\text { Wasserdampf- } \\
\text { destillation }\end{array}$ & $\begin{array}{l}\text { TAOMED }^{\circledR}, \\
\text { TAOASIS GmbH, } \\
\text { Detmold, } \\
\text { Deutschland }\end{array}$ \\
\hline Nelkenblütenöl & $\begin{array}{l}\text { Caryophylli } \\
\text { aetheroleum }\end{array}$ & $\begin{array}{l}\text { Syzygium aromati- } \\
\text { cum (L.) MERR ET } \\
\text { L.M. PERRY }\end{array}$ & $\begin{array}{l}\text { Cyzygium } \\
\text { aromaticum oil, } \\
\text { Eugenol, Geraniol, } \\
\text { Benzyl salicylate }\end{array}$ & Blüte & $\begin{array}{l}\text { Indien, } \\
\text { kontrollierter } \\
\text { Bio-Anbau }\end{array}$ & $\begin{array}{l}\text { Wasserdampf- } \\
\text { destillation }\end{array}$ & $\begin{array}{l}\text { TAOMED }^{\circledR}, \\
\text { TAOASIS GmbH, } \\
\text { Detmold, } \\
\text { Deutschland }\end{array}$ \\
\hline Zimtblätteröl & $\begin{array}{l}\text { Cinnamomi } \\
\text { aetheroleum }\end{array}$ & $\begin{array}{l}\text { Cinnamomum verum } \\
\text { J.S. PrESL }\end{array}$ & $\begin{array}{l}\text { Benzylbenzoat, } \\
\text { Eugenol, Limonen, } \\
\text { Linalool, } \\
\text { Zimtaldehyd, } \\
\text { Zimtalkohol }\end{array}$ & Blatt & $\begin{array}{l}\text { Madagaskar, } \\
\text { kontrollierter } \\
\text { Bio-Anbau }\end{array}$ & $\begin{array}{l}\text { Wasserdampf- } \\
\text { destillation }\end{array}$ & $\begin{array}{l}\text { Vertreiber: } \\
\text { Aromaland, } \\
\text { Inh. Gerda Foltis, } \\
\text { Röttingen- } \\
\text { Aufstetten, } \\
\text { Deutschland }\end{array}$ \\
\hline $\begin{array}{l}\text { Indisches } \\
\text { Melissenöl }\end{array}$ & $\begin{array}{l}\text { Cymbopogo- } \\
\text { nis nardi ae- } \\
\text { theroleum }\end{array}$ & $\begin{array}{l}\text { Cymbopogon nardus } \\
\text { (L.) RENDLE }\end{array}$ & $\begin{array}{l}\text { Cymbopogon } \\
\text { nardus oil, Geraniol, } \\
\text { Citronellol, } \\
\text { Limonene, Citral, } \\
\text { Linalool, Eugenol }\end{array}$ & Kraut & $\begin{array}{l}\text { Nepal, } \\
\text { kontrollierter } \\
\text { Bio-Anbau }\end{array}$ & $\begin{array}{l}\text { Wasserdampf- } \\
\text { destillation }\end{array}$ & $\begin{array}{l}\text { TAOMED }^{\circledR}, \\
\text { TAOASIS GmbH, } \\
\text { Detmold, } \\
\text { Deutschland }\end{array}$ \\
\hline Lemongrasöl & $\begin{array}{l}\text { Cymbopogo- } \\
\text { nis citrati } \\
\text { aetheroleum }\end{array}$ & $\begin{array}{l}\text { Cymbopogon } \\
\text { citratus (DC.) STAPF }\end{array}$ & $\begin{array}{l}\text { Cymbopogon citratus } \\
\text { oil }\end{array}$ & Blatt & $\begin{array}{l}\text { Indien, } \\
\text { kontrollierter } \\
\text { Bio-Anbau }\end{array}$ & $\begin{array}{l}\text { Wasserdampf- } \\
\text { destillation }\end{array}$ & $\begin{array}{l}\text { Baldini, TAOASIS } \\
\text { GmbH, Detmold, } \\
\text { Deutschland }\end{array}$ \\
\hline $\begin{array}{l}\text { Angelika- } \\
\text { wurzelöl }\end{array}$ & $\begin{array}{l}\text { Angelicae } \\
\text { aetheroleum }\end{array}$ & $\begin{array}{l}\text { Angelica } \\
\text { archangelica } \mathrm{L} .\end{array}$ & $\begin{array}{l}\text { Angelica archangelica } \\
\text { root oil, Limonene, } \\
\text { Linalool }\end{array}$ & Wurzel & $\begin{array}{l}\text { Frankreich, } \\
\text { kontrollierter } \\
\text { Bio-Anbau }\end{array}$ & $\begin{array}{l}\text { Wasserdampf- } \\
\text { destillation }\end{array}$ & $\begin{array}{l}\text { PRIMAVERA } \\
\text { LIFE GmbH, } \\
\text { Oy-Mittelberg, } \\
\text { Deutschland }\end{array}$ \\
\hline Palmarosaöl & $\begin{array}{l}\text { Cymbopogo- } \\
\text { nis martinii } \\
\text { aetheroleum }\end{array}$ & $\begin{array}{l}\text { Cymbopogon } \\
\text { martinii (Roхв.) } \\
\text { J.F. WATson }\end{array}$ & $\begin{array}{l}\text { Cymbopogon martinii } \\
\text { oil, Geraniol, Linalool, } \\
\text { Farnesol, Citral, } \\
\text { Limonene, Citronellol }\end{array}$ & Gras & $\begin{array}{l}\text { Nepal, } \\
\text { kontrollierter } \\
\text { Bio-Anbau }\end{array}$ & $\begin{array}{l}\text { Wasserdampf- } \\
\text { destillation }\end{array}$ & $\begin{array}{l}\text { TAOMED }^{\circledR} \text {, } \\
\text { TAOASIS GmbH, } \\
\text { Detmold, } \\
\text { Deutschland }\end{array}$ \\
\hline $\begin{array}{c}\text { Muskateller- } \\
\text { salbeiöl }\end{array}$ & $\begin{array}{l}\text { Salviae } \\
\text { sclareae } \\
\text { aetheroleum }\end{array}$ & Salvia sclarea $\mathrm{L}$. & $\begin{array}{l}\text { Salvia sclarea oil, } \\
\text { Linalool, Geraniol, } \\
\text { Limonene, Eugenol }\end{array}$ & Kraut & $\begin{array}{l}\text { Frankreich, } \\
\text { kontrollierter } \\
\text { Bio-Anbau }\end{array}$ & $\begin{array}{l}\text { Wasserdampf- } \\
\text { destillation }\end{array}$ & $\begin{array}{l}\text { TAOMED }^{\circledR}, \\
\text { TAOASIS GmbH, } \\
\text { Detmold, } \\
\text { Deutschland }\end{array}$ \\
\hline $\begin{array}{l}\text { Rosen- } \\
\quad \text { geranienöl }\end{array}$ & $\begin{array}{l}\text { Oleum } \\
\text { geranii }\end{array}$ & $\begin{array}{l}\text { Pelargonium graveo- } \\
\text { lens L Herit. EX } \\
\text { Ait. }\end{array}$ & $\begin{array}{l}\text { Pelargonium roseum } \\
\text { asperum oil, } \\
\text { Citronellol, Geraniol, } \\
\text { Linalool, Limonene }\end{array}$ & Blatt & $\begin{array}{l}\text { Ägypten, } \\
\text { kontrollierter } \\
\text { Bio-Anbau }\end{array}$ & $\begin{array}{l}\text { Wasserdampf- } \\
\text { destillation }\end{array}$ & $\begin{array}{l}\text { TAOASIS GmbH, } \\
\text { Detmold, } \\
\text { Deutschland }\end{array}$ \\
\hline
\end{tabular}

Tab. 3. Fortsetzung nächste Seite 
Tab. 3. Fortsetzung

\begin{tabular}{|c|c|c|c|c|c|c|c|}
\hline \multirow{2}{*}{$\begin{array}{l}\text { Ätherisches Öl, } \\
100 \% \text { naturrein }\end{array}$} & \multirow{2}{*}{$\begin{array}{l}\text { Wissen- } \\
\text { schaftlicher } \\
\text { Ölname }\end{array}$} & \multirow{2}{*}{$\begin{array}{l}\text { Botanischer Name } \\
\text { der Stammpflanze }\end{array}$} & \multicolumn{4}{|c|}{ Angaben nach Etikettierung des Herstellers } & \multirow[t]{2}{*}{ Hersteller } \\
\hline & & & Inhaltsstoffe (INCI) & Pflanzenteil & $\begin{array}{l}\text { Ursprungsland/ } \\
\text { Anbau }\end{array}$ & Gewinnung & \\
\hline Manukaöl & $\begin{array}{l}\text { Leptospermi } \\
\text { scoparii } \\
\text { aetheroleum }\end{array}$ & $\begin{array}{l}\text { Leptospermum sco- } \\
\text { parium J.R. ET G. } \\
\text { ForsT }\end{array}$ & $\begin{array}{l}\text { Leptospermum } \\
\text { scoparium leaf oil, } \\
\text { Limonene, Linalool, } \\
\text { Farnesol, Geraniol }\end{array}$ & Blatt & $\begin{array}{l}\text { Neuseeland, } \\
\text { Wildsammlung }\end{array}$ & $\begin{array}{l}\text { Wasserdampf- } \\
\text { destillation }\end{array}$ & $\begin{array}{l}\text { TAOMED }^{\circledR} \text {, } \\
\text { TAOASIS GmbH, } \\
\text { Detmold, } \\
\text { Deutschland }\end{array}$ \\
\hline Ravintsaraöl & $\begin{array}{l}\text { Cinnamomi } \\
\text { camphorae } \\
\text { aetheroleum }\end{array}$ & $\begin{array}{l}\text { Cinnamomum cam- } \\
\text { phora (L.) J.S. PREsL }\end{array}$ & $\begin{array}{l}\text { Commiphora } \\
\text { camphora leaf oil, } \\
\text { Limonene }\end{array}$ & Zweig & $\begin{array}{l}\text { Madagaskar, } \\
\text { kontrollierter } \\
\text { Bio-Anbau }\end{array}$ & $\begin{array}{l}\text { Wasserdampf- } \\
\text { destillation }\end{array}$ & $\begin{array}{l}\text { PRIMAVERA } \\
\text { LIFE GmbH, } \\
\text { Oy-Mittelberg, } \\
\text { Deutschland }\end{array}$ \\
\hline Lavendelöl fein & $\begin{array}{l}\text { Lavandulae } \\
\text { aetheroleum }\end{array}$ & $\begin{array}{l}\text { Lavandula angustifo- } \\
\text { lia MiLL. }\end{array}$ & $\begin{array}{l}\text { Lavandula } \\
\text { angustifolia oil, } \\
\text { Geraniol, Limonene, } \\
\text { Linalool }\end{array}$ & Kraut & $\begin{array}{l}\text { Frankreich, } \\
\text { kontrollierter } \\
\text { Bio-Anbau }\end{array}$ & $\begin{array}{l}\text { Wasserdampf- } \\
\text { destillation }\end{array}$ & $\begin{array}{l}\text { PRIMAVERA } \\
\text { LIFE GmbH, } \\
\text { Oy-Mittelberg, } \\
\text { Deutschland }\end{array}$ \\
\hline
\end{tabular}

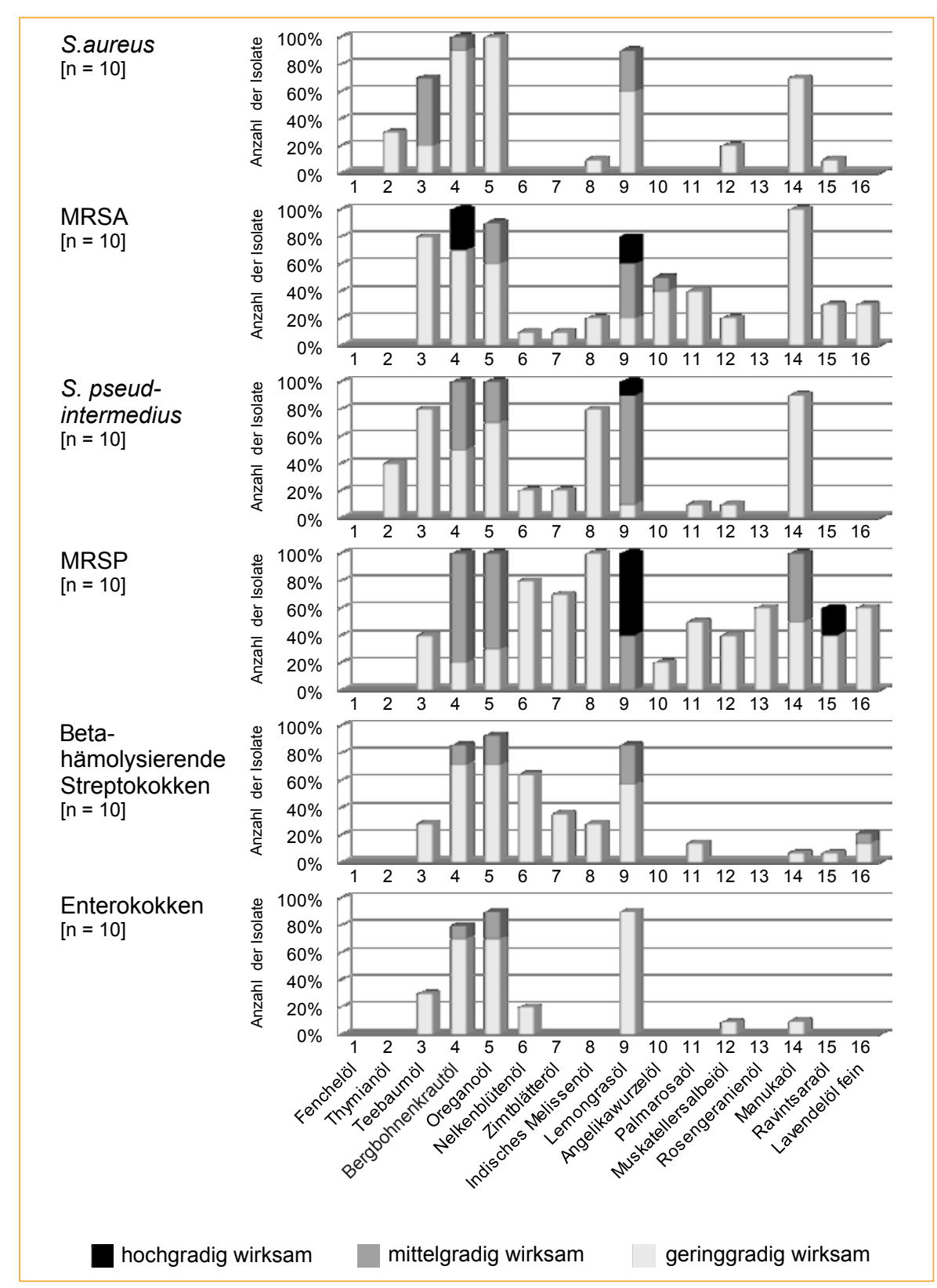

Abb. 1. In-vitro-Wirkung der ätherischen Öle gegen grampositive Erreger. S. aureus = Staphylococcus aureus; S. pseudintermedius $=$ Staphylococcus pseudintermedius; MRSA = Methicillin-resistente Stämme von S. aureus; MRSP = Methicillinresistente Stämme von S. pseudintermedius.

\section{S.aureus}

MRSA

$[\mathrm{n}=10]$

S. pseudintermedius $[\mathrm{n}=10]$

MRSP

$[\mathrm{n}=10]$

Beta-

Streptokokken [n $=10$

Enterokokken 


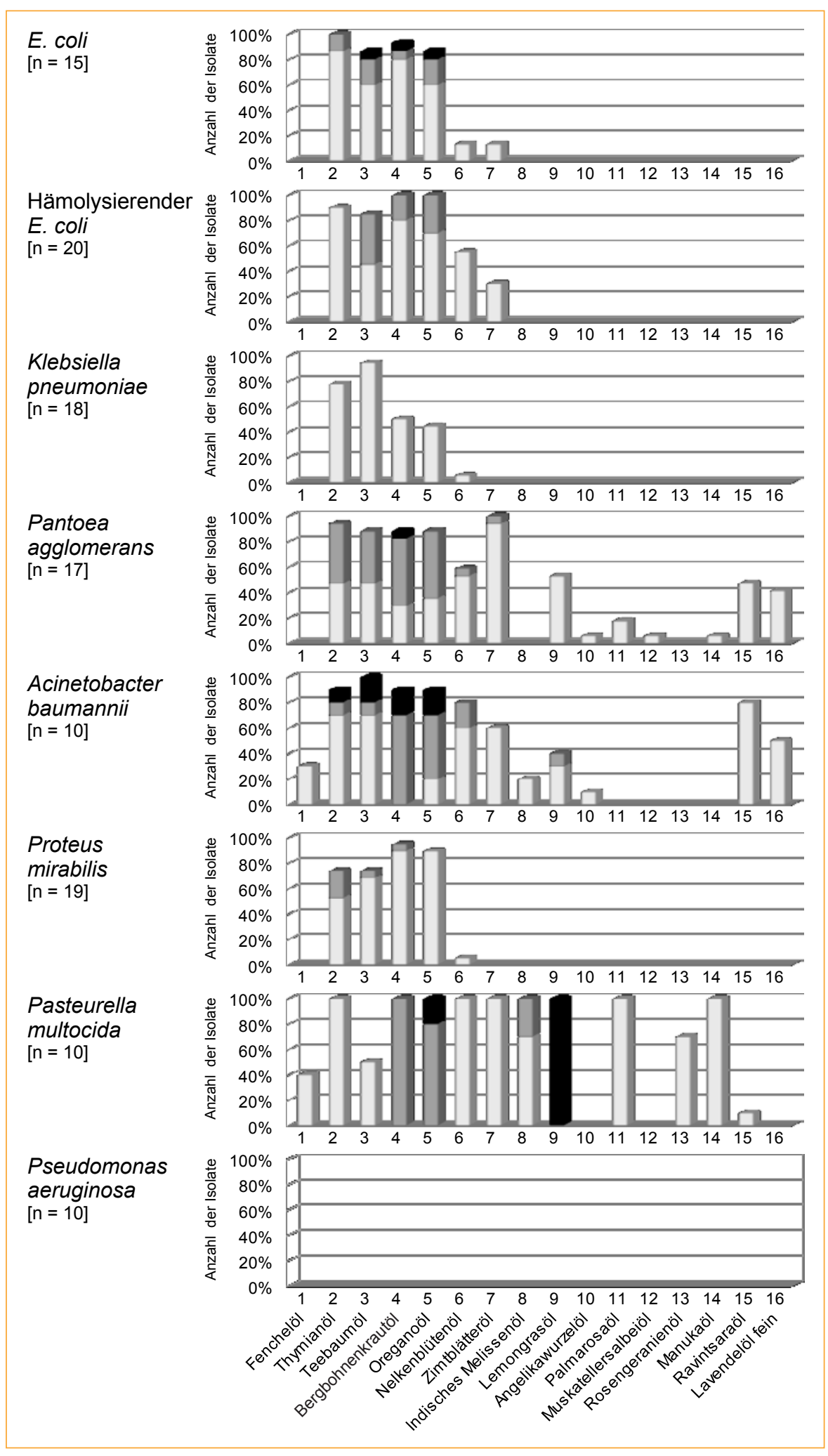

Abb. 2. In-vitro-Wirkung der ätherischen Öle gegen gramnegative Erreger. E. coli = Escherichia coli.

ringgradig. Fenchelöl zeigte keinerlei Wirksamkeit gegen grampositive Erreger.

Gegen gramnegative Erreger (Abb. 2) waren Thymian-, Teebaum-, Bergbohnenkraut- und Oreganoöl häufig mittel- oder geringgradig, teils sogar hochgradig wirksam. Nelkenblüten- und Zimtblätteröl zeigten häufig eine geringgradige Wirkung gegen
Pantoea agglomerans, Acinetobacter baumannii und Pasteurella multocida. Ravintsara- und Lavendelöl fein waren teils geringgradig wirksam gegen Pantoea agglomerans und Acinatobacter baumannii. Fenchel-, ind. Melissen-, Lemongras-, Angelikawurzel-, Palmarosa-, Muskatellersalbei-, Rosengeranien- und Manukaöl waren nie bis selten gering wirksam gegen gramnegative Erreger. 
Nur gegen Pasteurella multocida zeigten besonders Lemongrasöl eine hochgradige, ind. Melissenöl eine mittel- bis geringgradige und Palamarosa-, Manuka- und Rosengeranienöl häufig eine geringgradige Wirkung.

\section{Wirksamkeit gegen grampositive und gramnegative Erreger im}

Vergleich

Generell zeigten sich in der Empfindlichkeit der grampositiven und gramnegativen Erreger keine deutlichen Unterschiede. Nur einzelne ätherische Öle, wie z.B. das Lemongrasöl, hatten eine deutlich bessere Wirkung gegen grampositive Keime, während Thymianöl eine bessere Wirkung gegen gramnegative Keime zeigte.

\section{Wirksamkeit gegen multiresistente Erreger}

Für die MRSA und MRSP zeigte sich im Vergleich zu den Methicillin-empfindlichen Stämmen kein deutlicher Unterschied im Wirkspektrum der ätherischen Öle. Die MRSA- und MRSPStämme wiesen teils sogar Isolate auf, gegen die einige ätherische Öle geringgradig wirkten, die sonst gegen die nicht-Methicillin-resistenten Stämme nicht wirksam waren (Nelkenblüten-, Zimtblätter-, Angelikawurzel-, Palmarosa-, Muskatellersalbei-, Rosengeranien-, Ravintsara- und Lavendelöl fein).

\section{Diskussion}

Bei dem in dieser Studie angewandten Aromatogramm handelt es sich methodisch um einen Agardiffusionstest. Die Ermittlung der In-vitro-Wirksamkeit der ätherischen Öle erfolgte anhand der Größe der Hemmhofradien. Der Hemmhofradius des Bakterienwachstums um das mit Öl beschickte Filterpapierplättchen hängt, wie auch beim Agardiffusionstest eines Antibiotikums [31], einerseits von der Empfindlichkeit des getesteten Keims ab, andererseits aber auch von den Diffusionseigenschaften der einzelnen Wirkkomponenten im Agar. Beispielsweise wurde schon früh gezeigt, dass ein hoher Agaranteil im Medium zu einer schlechteren Löslichkeit der ätherischen Ölbestandteile und somit zu einem kleineren Hemmhofradius führt, und auch der $\mathrm{pH}$-Wert des Mediums kann einen Einfluss auf die Diffusion haben [32]. Lipophile Wirkkomponenten der ätherischen Öle, wie z.B. das Farnesol, zeigen ein schlechtes Ergebnis im Agardiffusionstest, aber ein gutes in der Mikrodilution [33].

Die Ergebnisse eines Agardiffusionstests sind qualitativer Natur und erlauben die Einteilung der In-vitro-Resultate in Wirksamkeitsstufen. Sie ermöglichen allerdings nicht die Bestimmung einer minimalen Hemmkonzentration (MHK) - da nicht zu bestimmen ist, welche Menge eines Wirkstoffs, sei es ein Antibiotikum oder Wirkkomponenten der ätherischen Öle, in den Agar diffundiert ist [34] - oder die Ermittlung einer therapeutisch relevanten Konzentration. Auch bakteriostatische oder bakterizide Effekte eines ätherischen Öls können so nicht ermittelt werden, da Wachstumsinhibition nicht mit bakteriellem Zelltod gleichzusetzen ist [34]. Zur Bestimmung der zuvor genannten Parameter sollte eine Reihenverdünnungsmethode mit ätherischen Ölen angewandt werden [35].
Im Gegensatz zum mittlerweile sowohl in der Humanmedizin als auch in der Veterinärmedizin gut standardisierten Agardiffusionstest für die Empfindlichkeitstestung von Antibiotika [30, 36, 37] gibt es für die Empfindlichkeitstestung ätherischer Öle keinen allgemein gültigen Standard. Resultate eines Agardiffusionstests mit ätherischen Ölen sollten deswegen vorsichtig interpretiert werden. Nichtsdestotrotz wird das Aromatogramm in Form des Agardiffusionstest als «Screeningmethode» $[27,38]$ und auch als praktikables diagnostisches Mittel vor einer Therapie genutzt, um prinzipiell in vitro wirksame ätherische Öle zu ermitteln [29].

Aufgrund der fehlenden Standardisierung sind die bisher publizierten Untersuchungen bezüglich der Wirksamkeit der ätherischen Öle nicht immer miteinander vergleichbar. Oft wurden eine unterschiedliche Methodik, verschiedene Keimstämme oder nicht identisch zusammengesetzte ätherische Öle verwandt.

In dieser Studie wurden $10 \mu \mathrm{l}$ pures ätherisches Öl im Agardiffusionstest genutzt, wie auch in anderen veterinärmedizinischen [18], humanmedizinischen [39] und lebensmittelchemischen [40, 41] Studien. Allerdings ist der Einsatz von unverdünntem ätherischem Öl zur Therapie nicht ratsam, da es hierbei schnell zu toxischen Effekten kommen kann [42]. Es gibt In-vitro- und In-vivoUntersuchungen zur Toxizität von ätherischen Ölen. Diese hauptsächlich humanmedizinischen Studien nutzten allerdings nicht selten Versuchstiere. Die Ergebnisse dieser Studien können somit auch bei Tieren angewandt werden. In einer humanmedizinischen Studie zur Ototoxizität von Teebaumöl führte die Instillation von 100\%igem Teebaumöl ins Mittelohr des Versuchstiers Meerschweinchen zu Schäden, während eine 2\%ige Verdünnung gut vertragen wurde [43]. Auch eine intratympanische Injektion von 3\%igem Teebaumöl wirkte beim Versuchstier Chinchilla nicht ototoxisch [44].

Die Zusammensetzung der ätherischen Öle kann je nach Wuchsort der Ursprungspflanze, klimatischen Bedingungen und Erntephase differieren [39, 45-48]. Diese unterschiedliche Zusammensetzung eines ätherischen Öls kann eine veränderte antibakterielle Wirksamkeit zur Folge haben [39, 46-48]. Somit gelten die Ergebnisse eines Aromatogramms genau genommen nur für den spezifisch von einem Patienten isolierten Keim und das getestete ätherische Öl einer Charge, das die gleiche Zusammensetzung hat [29].

Die Ergebnisse der vorliegenden Untersuchung verbinden dagegen eine große Zahl an ätherischen Ölen mit einem nahezu kompletten Spektrum tiermedizinisch bedeutsamer Keimisolate und bieten somit einen breiten Vergleich der Wirksamkeit und auch der Praxisrelevanz.

Die hier dargestellten Ergebnisse zeigen eine Wirksamkeit der ätherischen Öle gegen grampositive und gramnegative Erreger. Zuvor wurde bereits für ätherische Öle anderer Arzneipflanzen in humanmedizinischen [49] und lebensmittelchemischen Studien $[49,50]$ eine bessere Wirkung gegen grampositive Keime beschrieben. Es wird vermutet, dass gramnegative Bakterien aufgrund ihrer äußeren Phospholipidmembran weniger empfindlich gegen ätherische Öle sind. Grampositive Erreger dagegen verfügen über eine lipophile Zellwand, die für die ebenfalls lipophilen Komponenten 
der ätherischen Öle permeabel ist. Trotzdem können ätherische Öle, wie auch diese Studie zeigt, gut gegen gramnegative Keime wirksam sein

Für einzelne Bestandteile ätherischer Öle, wie z.B. das Carvacrol und das Thymol im Oreganoöl, wurde eine Wirkung gegen den grampositiven Keim S. aureus und den gramnegativen Keim P. aeruginosa festgestellt [51]. Die genannten Bestandteile führen zu einer erhöhten Permeabilität der bakteriellen Zellmembran mit nachfolgendem Verlust von lebenswichtigen Kaliumionen und einer $\mathrm{pH}$-Wert-Senkung durch den Ausstrom von Protonen [51, 52]. Zusätzlich erfolgt eine Depletion des zellulären Energieträgers Adenosintriphosphat, die wohl entweder auf einer verringerten Synthese, einer vermehrten Hydrolyse [51] oder auf einem Verlust über die Zellmembran beruht $[51,52]$.

Im Gegensatz dazu war bei den hier beschriebenen Untersuchungen keine Wirksamkeit der getesteten ätherischen Öle gegen $P$. aeruginosa zu verzeichnen. In einer anderen Studie zeigte sich ebenfalls keine Wirkung anderer ätherischer Öle gegen $P$. aeruginosa [53]. Diesem Trend entsprechend stellte sich in vielen humanmedizinischen/lebensmittelchemischen $[15,51,54]$ wie auch tiermedizinischen Studien $[18,26]$ P. aeruginosa als der resistenteste Keim dar, der z.B. nur gegen Thymian-, Oregano- oder Lemongrasöl empfindlich war.

Bemerkenswert ist hingegen die In-vitro-Wirksamkeit der ätherischen Öle gegen multiresistente Stämme wie MRSA und MRSP. Für Teebaumöl, Oreganoöl und einige Wirkstoffkomponenten wie das Carvacrol und Thymol wurde auch in humanmedizinischen Studien bereits eine Wirkung gegen MRSA-Stämme beschrieben $[55,56]$. In einer anderen umfangreichen humanmedizinischen Studie wiesen 78 von 91 getesteten ätherischen Ölen eine In-vitroAktivität gegen MRSA auf [38]. Manukaöl verfügte über eine antibakterielle Wirksamkeit gegen MRSP klinischer Isolate von an Pyodermie und Otitis externa erkrankten Hunden [22]. Somit könnten ätherische Öle aussichtsreiche Kandidaten für eine Alternativtherapie zu Antibiotika sein.

In einem Tiermodell für humane oberflächliche und subkutane S.-aureus-Hautinfektionen zeigten kurz nach subkutaner bakterieller Infektion ebenfalls subkutan injiziertes Zimt- und Nelkenöl eine keimreduzierende Wirkung im Vergleich zur nicht behandelten und sogar im Vergleich zur mit einem Antibiotikum (Gentamicin) behandelten Gruppe [57]. Hautcreme, die unter anderem Teebaumöl enthält, wirkte antibakteriell gegen aus Nasenlöchern von Hunden isolierten S. pseudintermedius [58].

Auch zur synergistischen Wirkung der ätherischen Öle mit Antibiotika gibt es Literaturhinweise aus der Humanmedizin. Ätherische Öle waren in vitro sogar in der Lage, entstandene bakterielle Resistenzen zu verringern. So konnte das ätherische Öl von Helichrysum italicum (italienische Strohblume), insbesondere der Wirkbestandteil Geraniol, in einer In-vitro-Studie die Empfindlichkeit multiresistenter gramnegativer Bakterien, z.B. E. coli, P. aeruginosa oder Acinetobacter baumanii, gegen Antibiotika wie Beta-Lactame, Quinolone und Chloramphenicol wiederherstellen [59]. Geranienöl zeigte mit dem Gyrasehemmer Norfloxacin eine synergistische Wirkung gegen S. aureus, jedoch nicht gegen E. coli [60]. Eu- genol, ein Hauptbestandteil von Nelkenöl, senkte die MHK von unterschiedlichen Antibiotika, z.B. Penicillin und Tetrazyklin, gegen gramnegative Keime wie E. coli und P. aeruginosa [61]. Auch für Carvacrol, ebenfalls ein Wirkbestandteil vieler ätherischer Öle, wurde eine synergistische Wirkung mit Penicillin gegen MRSA und E. coli beschrieben. Allerdings ergab dieselbe Studie, dass z.B. Thymol, unter anderem ein Inhaltstoff von Thymianöl, zusammen mit Penicillin sogar eine antagonistische Wirkung hat. Andere Inhaltsstoffe ätherischer Öle hatten wiederum keinerlei Einfluss auf die Wirkstärke von Antibiotika [62].

Zusätzlich können ätherische Öle auch über eine Biofilmwirksamkeit verfügen. Die Biofilmbildlung kann zu einer besseren Resistenz gegen die Wirtsabwehr und die antibiotische Therapie beitragen [63]. Dies gilt gleichermaßen für die Tiermedizin [64]. Oreganoöl, wie auch seine Wirkkomponenten Carvacrol und Thymol, zeigte in einer humanmedizinischen Studie eine Biofilm-inhibierende Wirkung gegen S.aureus, allerdings erst bei einer höheren Konzentration als zur Inhibierung des planktonischen Bakterienwachstums [65]. In einer anderen Studie inhibierte Carvacrol die Bildung eines Biofilms von S.aureus, allerdings nicht die von P. aeruginosa [66]. Manukaöl führte zu einer $>50 \%$ igen Bakterienreduktion von $S$. pseudintermedius, isoliert von an Pyodermie oder Otitis externa erkrankten Hunden, und erwies sich somit als potenter Biofilminhibitor [22].

Vor der therapeutischen Nutzung ätherischer Öle sollte jedoch die Verträglichkeit in Bezug auf die jeweilige Tierart und Lokalisation abgeklärt werden. Kenntnisse zur Anwendung von ätherischen Ölen beruhen in der Veterinärmedizin momentan vor allem auf Erfahrungswerten und Studien aus der Humanmedizin [67]. Die ätherischen Öle werden schnell oral oder dermal resorbiert, ihre Metabolisierung findet hauptsächlich in der Leber statt. Die Stoffwechselprodukte werden innerhalb von 48 bis $72 \mathrm{~h}$ über den Urin ausgeschieden, etwa $10 \%$ der Öle aber auch über den Kot [42]. Besonders die Katze kann im Vergleich zum Hund aufgrund ihrer Glucuronidierungsschwäche anfällig für Intoxikationen mit ätherischen Ölen, besonders mit phenolhaltigen, sein [68, 69]. Sehr häufig treten Vergiftungen durch Teebaumöl bei Katzen auf, kommen aber auch bei Hunden vor [32]. Allerdings können auch andere ätherische Öle unerwünschte Nebenwirkungen hervorrufen. Natürliche Flohprodukte in Form von Shampoos, Spot-ons und Sprays, die ein Mischung aus ätherischen Ölen (Lemongras-, Nelken-, Pfefferminz-, Rosmarin-, Thymian-, Zedernholz- und Zimtöl) enthielten, führten vermehrt bei Katzen, aber auch bei Hunden zu klinischen Erscheinungen [70].

\section{Schlussfolgerung}

Auch wenn Ergebnisse von In-vitro-Testungen, wie dem hier angewandten Aromatogramm, aus den genannten Gründen nur eingeschränkt die klinische Wirksamkeit ätherischer Öle vorhersagen können, lassen die vorliegenden Resultate den Schluss zu, dass die spezifische Wirksamkeit eines ätherischen Öls gegen pathogene Keime eines individuellen Patienten vor Therapiebeginn im Labor 
getestet werden sollte. Das heißt, vor einer Therapie sollte geeignetes Material für eine bakteriologische Untersuchung durch den Tierarzt entnommen und diese anschließend im Labor durchgeführt werden. Für die isolierten Keime kann dann ein Aromatogramm erstellt werden. Außer im Fall von P. aeruginosa, bei dem sich alle ätherischen Öle in vitro als unwirksam zeigten, sollte die Wirksamkeit vor der Therapie getestet werden, da sich keine definitive sehr gute Wirksamkeit eines Öls gegen einen bestimmten Keim vorhersagen lässt.

Ätherische Öle stellen, wie in dieser Studie anhand ihrer In-vitro-Wirkung belegt wurde, auch in der Tiermedizin eine Alternative zu antibiotischen Therapien oder zumindest eine ergänzende Therapiemöglichkeit dar. Sie könnten insbesondere gegen multiresistente Keime eingesetzt werden, je nach Anwendungsmöglichkei- ten bei der entsprechenden Tierart. Therapien mit ätherischen Ölen könnten somit auch zu einer Reduzierung des Antibiotikaeinsatzes beitragen und neuen Resistenzentwicklungen vorbeugen.

\section{Online Supplemental Material}

Online Supplemental Table To access the supplemental table, please refer to $w w w$. karger.com/?DOI $=465519$.

\section{Disclosure Statement}

Die Autoren sind Mitarbeiter von Laboklin GmbH \& Co. KG.

\section{Literatur}

1 Löscher W, Bäumer W (eds): Pharmakotherapie be Haus- und Nutztieren, ed 9. Stuttgart, Enke, 2014

2 Reichling J, Schnitzler P, Suschke U, Saller R: Essential oils of aromatic plants with antibacterial, antifungal, antiviral, and cytotoxic properties - an overview. Forsch Komplementmed 2009;16:79-90.

3 George DR, Guy JH, Arkle S, Harrington D, de Luna C, Okello EJ, Shiel RS, Port G, Sparagano OAE: Use of plant-derived products to control arthropods of veterinary importance: a review. Ann N Y Acad Sci 2008; 1149:23-26.

4 Ferguson CE, Kleinman HF, Browning J: Effect of lavender aromatherapy on acute-stressed horses. J Equine Vet Sci 2013;33:67-69.

5 Buchbauer G, Jirovetz L, Jager W, Dietrich H, Plank C: Aromatherapy: evidence for sedative effects of the essential oil of lavender after inhalation. Z Naturforsch C 1991;46:1067-1072.

6 Komiya M, Sugiyama A, Tanabe K, Uchino T, Takeuchi T: Evaluation of the effect of topical application of lavender oil on autonomic nerve activity in dogs. Am J Vet Res 2009;70:764-769.

7 Hawken PAR, Fiol C, Blache D: Genetic differences in temperament determine whether lavender oil alleviates or exacerbates anxiety in sheep. Physiol Behav 2012; 105:1117-1123.

8 Tretter S, Mueller RS: The influence of topical unsaturated fatty acids and essential oils on normal and atopic dogs. J Am Anim Hosp Assoc 2011;47:236-240.

9 Blaskovic M, Rosenkrantz W, Neuber A, Sauter-Louis C, Mueller RS: The effect of a spot-on formulation containing polyunsaturated fatty acids and essential oils on dogs with atopic dermatitis. Vet J 2014;199:39-43.

10 Fitzi J, Furst-Jucker J, Wegener T, Saller R, Reichling J: Phytotherapy of chronic dermatitis and pruritus of dogs with a topical preparation containing tea tree oil (Bogaskin). Schweiz Arch Tierheilkd 2002;144:223231.

11 Bensignor E, Fabries L, Bailleux L: A split-body, randomized, blinded study to evaluate the efficacy of a topical spray composed of essential oils and essential fatty acids from plant extracts with antimicrobial properties. Vet Dermatol 2016;27:464-e123.

12 Girão V, Nunes-Pinheiro D, Morais SM, Sequeira JL, Gioso MA: A clinical trial of the effect of a mouth-rinse prepared with Lippia sidoides Cham essential oil in dogs with mild gingival disease. Prev Vet Med 2003;59: 95-102.
13 Kawakami E, Washizu M, HiranoT, Sakuma M, Takano M, Hori T, Tsutsui T: Treatment of prostatic abscesses by aspiration of the purulent matter and injection of tea tree oil into the cavities in dogs. J Vet Med Sci 2006;68:1215-1217.

14 Deans SG, Ritchie G: Antibacterial properties of plant essential oils. Int J Food Microbiol 1987;5:165-180.

15 Hammer KA, Carson CF, Riley TV: Antimicrobial activity of essential oils and other plant extracts. J Appl Microbiol 1999;86:985-990.

16 Cowan MM: Plant products as antimicrobial agents. Clin Microbiol Rev 1999;12:564-582.

17 Dorman HJ, Deans SG: Antimicrobial agents from plants: antibacterial activity of plant volatile oils. J Appl Microbiol 2000;88:308-316.

18 Rusenova N, Parvanov P: Antimicrobial activities of twelve essential oils against microorganisms of veterinary importance. Trakia J Sci 2009;7:37-43.

19 Mickienė R, Bakutis B, Baliukonienė V: Antimicrobial activity of two essential oils. Ann Agric Environ Med 2011;18:139-144.

20 Singh BR: Evaluation of antibacterial activity of Salvia officinalis L. sage oil on veterinary clinical isolates of bacteria. Noto-are Med 2013;15341289.

21 Singh BR: Antimicrobial activity of Rose Geranium (Pelargonium roseum) essential oil on bacteria of veterinary clinical origin. AJPTI 2015;13:1-5. www.asianpharmtech.com (letzter Abruf 2. Juni 2017).

22 Song C, Nam E, Park S, Hwang C: In vitro efficacy of the essential oil from Leptospermum scoparium (manuka) on antimicrobial susceptibility and biofilm formation in Staphylococcus pseudintermedius isolates from dogs. Vet Dermatol 2013;24:404-408, e87.

23 Ogunshe AO, Emikpe BO, Olayiwola JO, Adeyeri SO: Potentials of essential oils and plant extracts as bioantimicrobials on gram-negative indicator bacterial pathogens of poultry origin. J Vet Med Anim Health 2011;8: 112-119.

24 Dal Pozzo M, Silva Loreto É, Flores Santurio D, Hartz Alves S, Rossatto L, Castagna de Vargas A, Viegas J, Matiuzzi da Costa M: Antibacterial activity of essential oil of cinnamon and trans-cinnamaldehyde against Staphylococcus spp. isolated from vlinical mastitis of cattle and goats. Acta Sci Vet 2012;40:1-5.

25 Choi JY, Damte D, Lee SJ, Kim JC, Park SC: Antimicrobial activity of lemongrass and oregano essential oil against standard antibiotic resistant Staphylococcus aureus and field isolates from chronic mastitis cow. Int J Phytomed 2012;4:134-139.
26 Niculae M, Spinu M, Sandru CD, Brudasca F, Cadar D, Szakacs B, Scurtu I, Bolfa P, Mates CI: Antimicrobial potential of some Lamiaceae essential oils against animal multiresistant bacteria. Lucrari Stiintifice Medicina Veterinara 2009;17:170-175

27 Burt S: Essential oils: their antibacterial properties and potential applications in foods - a review. Int J Food Microbiol 2004;94:223-253.

28 Werner M, von Braunschweig R: Praxis Aromatherapie: Grundlagen - Steckbriefe - Indikationen, ed 2. Stuttgart, Haug, 2009.

29 Zimmermann E: Aromatherapie für Pflege- und Heilberufe: Kursbuch für Ausbildung und Praxis, ed 6 Stuttgart, Haug Fachbuch, 2016.

30 Clinical and Laboratory Standards Institute: VET01S: Performance Standards for Antimicrobial Disk and Dilution Susceptibility Tests for Bacteria Isolated from Animals, ed 3. Wayne, PA, Clinical and Laboratory Standards Institute, 2015.

31 Jorgensen JH, Ferraro MJ: Antimicrobial susceptibility testing: a review of general principles and contemporary practices. Clin Infect Dis 2009;49:1749-1755.

32 Janssen AM, Scheffer JJC, Svendsen AB: Antimicrobial activities of essential oils. Pharmaceutisch Weekblad Scientific Edition 1987;9:193-197.

33 Buchbauer G, Bașer KHC (eds): Handbook of Essential Oils: Science, Technology, and Applications, ed 2. Boca Raton, FL, CRC Press/Taylor \& Francis, 2016.

34 Balouiri M, Sadiki M, Ibnsouda SK: Methods for in vitro evaluating antimicrobial activity: a review. J Pharm Anal 2016;6:71-79.

35 Janssen AM, Chin NLJ, Scheffer JJC, Svendsen AB: Screening for antimicrobial activity of some essential oils by the agar overlay technique. Pharmaceutisch Weekblad Scientific Edition 1986;8:289-292.

36 Bauer AW, Kirby WM, Sherris JC, Turck M: Antibiotic susceptibility testing by a standardized single disk method. Am J Clin Pathol 1966;45:493-496.

37 Clinical and Laboratory Standards Institute: M02-A12: Performance Standards for Antimicrobial Disk Susceptibility Test; Approved Standard, ed 12. Wayne, PA, Clinical and Laboratory Standards Institute, 2015.

38 Chao S, Young G, Oberg C, Nakaoka K: Inhibition of methicillin-resistant Staphylococcus aureus (MRSA) by essential oils. Flavour Fragr J 2008;23:444-449.

39 Demuner AJ, Barbosa LCA, Magalhaes CG, da Silva CJ, Maltha CRA, Pinheiro AL: Seasonal variation in the chemical composition and antimicrobial activity of volatile oils of three species of Leptospermum (Myrtaceae) grown in Brazil. Molecules 2011;16:1181-1191. 
40 Amatiste S, Sagrafoli D, Giacinti G, Rosa G, Carfora V, Marri N, Tammaro A, Bovi E, Rosati R: Antimicrobial activity of essential oils against Staphylococcus aureus in fresh sheep cheese. Ital J Food Saf 2014;3:1696.

41 Maida I, Lo Nostro A, Pesavento G, Barnabei M, Calonico C, Perrin E, Chiellini C, Fondi M, Mengoni A, Maggini V, Vannacci A, Gallo E, Bilia AR, Flamini G, Gori L, Firenzuoli F, Fani R: Exploring the anti-Burkholderia cepacia complex activity of essential oils: a preliminary analysis. Evid Based Complement Alternat Med 2014;2014:573518.

42 Plumlee KH (ed): Clinical veterinary toxicology. St. Louis, MO, Mosby, 2004.

43 Zhang SY, Robertson D: A study of tea tree oil ototoxicity. Audiol Neurootol 2000;5:64-68.

44 Bezdjian A, Mujica-Mota MA, Azzi M, Daniel SJ: Assessment of ototoxicity of tea tree oil in a chinchilla animal model. Int J Pediatr Otorhinolaryngol 2014;78: 2136-2139.

45 McGimpsey JA, Douglas MH, van Klink JW, Beauregard DA, Perry NB: Seasonal variation in essential oil yield and composition from naturalized thymus vulgaris L. in New Zealand. Flavour Fragr J 1994;9:347-352.

46 Lis-Balchin M, Deans SG, Eaglesham E: Relationship between bioactivity and chemical composition of commercial essential oils. Flavour Fragr J 1998;13:98-104.

47 Cosentino S, Tuberoso CIG, Pisano B, Satta M, Mascia V, Arzedi E, Palmas F: In-vitro antimicrobial activity and chemical composition of Sardinian Thymus essential oils. Lett Appl Microbiol 1999;29:130-135.

48 Marotti M, Piccaglia R, Giovanelli E, Deans SG, Eaglesham E: Effects of planting time and mineral fertilization on peppermint (mentha $x$ piperita 1 .) essential oil composition and its biological activity. Flavour Fragr J 1994;9:125-129.

49 Nostro A, Germano MP, D’Angelo V, Marino A, Cannatelli MA: Extraction methods and bioautography for evaluation of medicinal plant antimicrobial activity. Lett Appl Microbiol 2000;30:379-384.

50 Hsouna AB, Hamdi N, Halima NB, Abdelkafi S: Characterization of essential oil from Citrus aurantium $\mathrm{L}$. flowers: antimicrobial and antioxidant activities. J Oleo Sci 2013;62:763-772.
51 Lambert R, Skandamis PN, Coote PJ, Nychas G: A study of the minimum inhibitory concentration and mode of action of oregano essential oil, thymol and carvacrol. J Appl Microbiol 2001;91:453-462.

52 Heipieper HJ: Effect of environmental factors on the trans/cis ratio of unsaturated fatty acids in Pseudomonas putida S12. Appl Environ Microbiol 1996;62: 2773-2777.

53 Sandri IG, Zacaria J, Fracaro F, Delamare A, Echeverrigaray S: Antimicrobial activity of the essential oils of Brazilian species of the genus Cunila against foodborne pathogens and spoiling bacteria. Food Chem 2007;103: 823-828.

54 Martino L de, Feo V de, Nazzaro F: Chemical composition and in vitro antimicrobial and mutagenic activities of seven Lamiaceae essential oils. Molecules 2009;14: 4213-4230.

55 Carson CF, Cookson BD, Farrelly HD, Riley TV: Susceptibility of methicillin-resistant Staphylococcus aureus to the essential oil of Melaleuca alternifolia. J Antimicrob Chemother 1995;35:421-424.

56 Nostro A, Blanco AR, Cannatelli MA, Enea V, Flamini G, Morelli I, Sudano Roccaro A, Alonzo V: Susceptibility of methicillin-resistant staphylococci to oregano essential oil, carvacrol and thymol. FEMS Microbiol Lett 2004;230:191-195.

57 Naveed R: In vitro and in vivo evaluation of antimicrobial activities of essential oils extracted from some indigenous spices. Pak Vet J 2013;33:413-417.

58 Han JI, Park SJ, Kim SG, Park HM: Antimicrobial effects of topical skin cream containing natural oil mixtures against Staphylococcus pseudintermedius and Malassezia pachydermatis. Vet Med Czech 2015;60: 202-207.

59 Lorenzi V, Muselli A, Bernardini AF, Berti L, Pagès J, Amaral L, Bolla J: Geraniol restores antibiotic activities against multidrug-resistant isolates from gram-negative species. Antimicrob Agents Chemother 2009;53: 2209-2211.
60 Rosato A, Vitali C, Laurentis N de, Armenise D, Antonietta Milillo M: Antibacterial effect of some essential oils administered alone or in combination with Norfloxacin. Phytomedicine 2007;14:727-732.

61 Hemaiswarya S, Doble M: Synergistic interaction of eugenol with antibiotics against Gram negative bacteria. Phytomedicine 2009;16:997-1005.

62 Gallucci N, Casero C, Oliva M, Zygadlo J, Demo M: Interaction between terpenes and penicillin on bacterial strains resistant to beta-lactam antibiotics. Molecul Med Chem 2006;30-32.

63 Costerton JW, Lewandowski Z, Caldwell DE, Korber DR, Lappin-Scott HM: Microbial biofilms. Annu Rev Microbiol 1995;49:711-745.

64 Jacques M, Aragon V, Tremblay YDN: Biofilm formation in bacterial pathogens of veterinary importance. Anim Health Res Rev 2010;11:97-121.

65 Nostro A, Sudano Roccaro A, Bisignano G, Marino A, Cannatelli MA, Pizzimenti FC, Cioni PL, Procopio F, Blanco AR: Effects of oregano, carvacrol and thymol on Staphylococcus aureus and Staphylococcus epidermidis biofilms. J Med Microbiol 2007;56:519-523.

66 Burt SA, Ojo-Fakunle VTA, Woertman J, Veldhuizen EJA: The natural antimicrobial carvacrol inhibits quorum sensing in Chromobacterium violaceum and reduces bacterial biofilm formation at sub-lethal concentrations. PLoS One 2014;9:e93414.

67 Reichling J, Frater-Schröder M, Saller R, Fitzi-Rathgen J, Gachnian-Mirtscheva R: Heilpflanzenkunde für die Veterinärpraxis, ed 3. Berlin, Heidelberg, Springer, 2016.

68 Villar D, Knight MJ, Hansen SR, Buck WB: Toxicity of melaleuca oil and related essential oils applied topically on dogs and cats. Vet Hum Toxicol 1994;36:139-142.

69 Bischoff K, Guale F: Australian tea tree (Melaleuca alternifolia) oil poisoning in three purebred cats. J Vet Diagn Invest 1998;10:208-210. 